\title{
Agentes Sociais no Paraná ${ }^{\dagger}$
}

Francisco Magalhães Filho

O propósito deste trabalho é discutir os agentes sociais presentes na sociedade paranaense, os interesses que defendem, seu papel, suas origens, suas forças relativas e o poder que possuem para influenciar, positiva ou negativamente, a evolução futura dessa sociedade.

Os agentes sociais são indivíduos agrupados na defesa de interesses comuns de qualquer tipo, e que agem coletivamente na sociedade para conseguir seus objetivos, atuando nas múltiplas instâncias da organização social ou à margem delas. O conceito inclui qualquer situação desse tipo, independentemente do número de indivíduos, de suas formas de organização, da relevância de seus objetivos e da força efetiva que detenham em cada momento. Claro que, para uma discussão como a que este trabalho se propõe a fazer, só serão levados em conta aqueles agentes cuja força é suficiente para que seus interesses e objetivos possam efetivamente influenciar de forma significativa a evolução da sociedade como um todo.

Estamos nos referindo a classes sociais e a suas frações, bem como a camadas ou estratos sociais que agem no espaço político por meio de partidos ou movimentos políticos de qualquer tipo, para manter, ampliar ou conquistar o controle do Estado e de seus aparelhos. Incluem-se também como agentes sociais organizações de classe ou categorias, como sindicatos e associações, que diretamente, ou por meio de suas vinculações com partidos e movimentos políticos, agem para obter o atendimento de reivindicações ou interesses específicos das classes ou categorias profissionais que representam.

A esse tipo de agentes, inteiramente inseridos no que poderíamos chamar de espaço político, deve-se acrescentar os movimentos sociais, cuja organização e orientação não é necessariamente política, ainda que possam manter ligações ou realizar ações conjuntas com os agentes políticos, e que muitos de seus objetivos só possam vir a ser alcançados na esfera política. São movimentos voltados para o atingimento de alguns poucos objetivos claramente definidos, que se esgotam ao alcançá-los, ainda que, em alguns casos, possam vir a transformarse em movimentos políticos e, em alguns casos (como o dos ecologistas), a levar à organização de partidos. Aqui estão incluídos, além dos ecologistas, movimentos e organizações como as comunidades eclesiais de base, os sem-terra, os sem-teto: defensores de direitos civis, da mu-

\footnotetext{
${ }^{\dagger}$ Artigo originalmente publicado na Revista Paranaense de Desenvolvimento (MAGALHÃES FILHO, Francisco. Agentes Sociais no Paraná. Revista Paranaense de Desenvolvimento. Curitiba: IPARDES, n.86, p.3-33, set./ dez.1995.)
} 
lher, da criança, das minorias, dos consumidores, e muitos outros, cuja proliferação e crescente presença na sociedade moderna (especialmente na América Latina) é fenômeno relativamente recente e de grande relevância para a prospecção e o planejamento do futuro.

Digamos que esse é o elenco de atores que estão teoricamente disponíveis para a montagem da peça que pretendemos apresentar. Ao levantarmos o pano, porém, iremos montando a peça ao longo de duas linhas fundamentais: quais desses atores estão ou estiveram efetivamente presentes, desde quando, por que, e com que desempenho até agora, bem como se esse desempenho é e tem sido influenciado pelos atores dos muitos outros palcos dos quais o Paraná ou é contíguo ou neles está inserido.

Para isso iremos começar por um resumo da evolução, das contradições e dos conflitos que marcaram a sociedade paranaense, desde, pelo menos, o momento em que ganhou a relativa autonomia representada pelo status provincial. Precisamos também verificar como os agentes locais interagiam ou interagem com o que acontece no Brasil como um todo.

A emancipação política do Paraná dá-se num momento em que começam a definir-se as duas frações da classe dominante local que irão disputar ou compartilhar o poder político na província e no estado federado por pouco mais de um século. De um lado, os comerciantes de gado e os grandes proprietários de terra; do outro, os exportadores e, com crescente importância ao longo de todo o período, as indústrias da erva-mate.

Em meados do século XIX o chamado tropeirismo - comércio interprovincial de animais - havia atingido seu apogeu com o crescimento da demanda no Sudeste, decorrente da expansão da economia cafeeira, fortalecendo tanto os que se dedicavam diretamente ao comércio quanto os que alugavam suas terras para a invernada das tropas. Por outro lado, a produção de erva-mate cancheada (semi-elaborada) vinha crescendo ao longo das décadas anteriores, estimulada pela exportação para os mercados platinos, e já se iniciava a produção do mate beneficiado (atividade de caráter industrial) e sua exportação para o Uruguai e o Chile.

Essas duas frações de classe que, para evitar uma longa controvérsia, podemos chamar, de forma pouco acadêmica, de frações de uma burguesia incipiente, serão, em resultado de seus interesses, e na interação de seus conflitos e acordos, os agentes principais da evolução da economia do Paraná e da formação e configuração de sua sociedade até os anos quarenta deste século.

Durante o período imperial, assim como nas primeiras décadas republicanas, esse é o que poderíamos chamar, sacrificando um pouco a precisão do conceito, de "bloco no poder" no Paraná. Ainda que desempenhe um papel secundário e subordinado em relação aos dois blocos que sucessivamente concentraram o poder no nível nacional, e dos quais faz parte: o 
primeiro até a abolição do trabalho escravo, e o segundo, do "segundo quadriênio" em diante.

Assim, todas as iniciativas e políticas no sentido do que hoje chamaríamos de "desenvolvimento" do Paraná adotadas no período, como construção de estradas de rodagem e de ferrovias, fomento à imigração europeia, incluindo a cessão de terras para o estabelecimento dos colonos, esforços para ampliar a ocupação do território, ampliação do sistema educacional, concessões a capitais externos não somente para serviços públicos urbanos, mas também para a exploração de recursos naturais, como a madeira, não apenas atendiam às necessidades e interesses concretos das frações de classe no poder (como o melhor acesso aos mercados, no caso das ferrovias, ou a valorização das terras circundantes, em muitos dos casos de estabelecimento de colônias), como conformavam-se com as concepções ideológicas da classe dominante do País e as políticas dos sucessivos governos nacionais, como o "branqueamento" da população, a produção de alimentos para a crescente população urbana, a ocupação do território como política de afirmação de soberania e de defesa militar, principalmente no Sul, e assim por diante.

No transcorrer desse longo período são raros os conflitos entre as duas frações de classe que escapam ao controle do mecanismo de acordos e compensações que caracteriza o sistema político brasileiro de então, principalmente durante o regime imperial. Apenas durante a Revolução Federalista, na fase de transição de um bloco hegemônico nacional para outro, é que os conflitos se acirram, ainda que provocados pela eclosão de uma guerra civil de caráter nacional. Como muitos liberais apoiaram o movimento rebelde, e parte da burguesia do mate era liberal, quando os combates chegaram ao Paraná houve lutas e fuzilamentos envolvendo as frações de classe dominantes. Com a normalização da situação política no país e a consolidação do novo bloco no poder no nível nacional, o sistema local se recompõe.

Por outro lado, a evolução da economia do Paraná ao longo do período foi passando por graduais, mas significativas, transformações que se traduziram necessariamente em mudanças na correlação de forças entre as duas frações de classe no poder. Enquanto o comércio de animais entrava em declínio marcante e a pecuária extensiva mantinha-se relativamente estagnada, a economia ervateira expandia-se de forma significativa, atingindo seu apogeu na década de 20. Em torno e a partir da indústria ervateira consolida-se uma burguesia industrial, comercial e financeira, reforçada pela crescente exploração madeireira e pelos segmentos industriais dela decorrentes e pelo surgimento de todo um leque de pequenas e médias indústrias de bens de consumo corrente, em grande parte originário da formação artesanal de muitos imigrantes europeus. Essa burguesia, outrora incipiente e agora ampliada e diversificada, mas ainda centrada principalmente na indústria ervateira, vai lentamente se impondo como força hegemônica no que chamamos de "bloco no poder" paranaense. A partir dos efeitos provocados pela Primeira 
Guerra Mundial, com o que poderíamos chamar de substituição forçada de importações e o crescimento das exportações, sua acumulação se acelera e serve de base para a consolidação dessa hegemonia que, como veremos, será de curta duração.

E os outros agentes sociais? Seus papéis, como tal, são de início muito limitados por seu tamanho pequeno, sua dispersão territorial e sua quase completa falta de organização. Não podemos esquecer que, por mais que o trabalho escravo não desempenhasse, nem no comércio de animais, nem da economia ervateira, papel proporcionalmente semelhante ao que teve em economias como as do açúcar e do café, por exemplo, sua presença amortecia a capacidade de organização e ação das camadas mais pobres. Por outro lado, a inexistência de centros urbanos, economicamente estruturados como tais, não permitia o surgimento sequer de corporações de ofício organizadas, do tipo das que participaram ativamente na vida política de Salvador e Recife, por exemplo. Esse mesmo fator limitou também, e muito, o surgimento de uma pequena burguesia, enquanto as chamadas classes médias tradicionais (profissionais liberais e altos funcionários públicos), além de pequenas eram em grande parte formadas por indivíduos oriundos da classe dominante. Quanto ao campo, onde a maioria vivia, a população trabalhadora, além de rarefeita, era composta principalmente por agregados e moradores das grandes propriedades ou por moradores de terras públicas, muitas vezes itinerantes.

Só com a expansão referida anteriormente é que a sociedade vai se tornando mais complexa. As colônias de agricultores europeus, ali onde têm sucesso, começam a conformar uma camada de pequenos proprietários cuja produção vai direcionar-se cada vez mais para os mercados urbanos, gestando inclusive uma pequena burguesia rural (nas que fracassam, os que não emigram permanecem na pequena produção de subsistência). Algo semelhante começa a acontecer no nordeste do Estado, o chamado "Norte Velho", para onde a cafeicultura paulista começa a expandir-se ao final do século, com fazendas de café empregando trabalho assalariado (chamados também de "colonos", termo que aqui tem significado diferente do que nas outras regiões), e também com uma pequena burguesia rural e uma pequena produção, só que aqui com migrantes vindos principalmente de Minas Gerais e São Paulo.

O crescimento das cidades, principalmente Curitiba, e a diversificação da vida urbana, leva ao surgimento e à expansão de uma pequena burguesia, em grande parte formada de imigrantes ou seus descendentes, que inclui comerciantes, principalmente lojistas, bem como pequenos industriais como os já mencionados anteriormente, além de artesãos das mais variadas profissões. O mesmo se dá com as classes médias tradicionais, nas quais cresce o número de profissionais liberais oriundos da imigração e o de funcionários públicos.

Mas, em termos sociológicos, o mais importante é o surgimento efetivo da classe 
operária decorrente de toda essa expansão econômica. Em primeiro lugar, com o crescimento da indústria ervateira e, mais importante ainda em termos de emprego, da indústria madeireira em todos os seus ramos e da indústria de produtos alimentares. Igualmente importantes, por levar a sua concentração espacial, são a expansão das estradas de ferro e os investimentos no melhoramento dos portos de Paranaguá e Antonina, bem como a expansão dos serviços públicos urbanos.

Como parte significativa dessa classe nascente é de origem europeia, muitos de seus componentes trazem consigo a experiência das lutas de classes e a cultura operária de seus países de origem. Não só há entre eles alguns sociais-democratas, anarquistas, e até fourrieristas, como muitos têm experiências de organização dos trabalhadores em sociedades beneficentes e de auxílio mútuo, bem como na defesa de seus interesses. Convivendo em uma sociedade em que a mera noção de direitos trabalhistas ou era desconhecida ou reprimida pelos aparelhos de Estado, e dado o caráter incipiente da própria classe, que na maioria dos casos sequer se via ainda como tal, sua ação na sociedade foi limitadíssima, a não ser na criação das referidas sociedades beneficentes, ali onde os imigrantes, principalmente alemães e italianos, eram maioria, e muitas vezes circunscritas ao grupo nacional que as fundara.

Todo esse quadro muda a partir de 1930.

O Paraná, ou seja, os agentes presentes em sua sociedade, tem um papel praticamente irrelevante tanto nos movimentos políticos que agitam a década de vinte quanto na composição da Aliança Liberal, que reúne algumas classes dominantes estaduais dispostas a enfrentar a crescente hegemonia da fração de classe dominante no bloco no poder nacional, do qual a burguesia paranaense fazia parte. Quando a crise política se agrava, levando ao levante armado, a sua vitória e à configuração de um novo bloco, que é o produto da alteração da correlação de forças no seio do anterior, mais a incorporação de novas frações de classe, antes excluídas, a fração que vinha consolidando sua hegemonia no Paraná - a burguesia de origem ervateira - está dele excluída.

Isso significou a perda não apenas da influência política que, embora pequena, detinha junto ao governo federal, como de seu controle e presença no governo estadual. Durante o longo período das interventorias, que se estende de 1930 a 1947, e que traduz a perda de autonomia das frações de classe dominantes nos estados e sua subordinação, em maior ou menor grau, ao bloco hegemônico nacional, seu lugar foi ocupado, pelo menos na cena política, pela outra fração que com ela dividira anteriormente o poder, a fração burguesa originária do comércio de animais e da pecuária dos Campos Gerais.

Quando a autonomia estadual é resgatada, com a Constituição de 1946, a base econômica e a sociedade paranaenses já haviam passado por tantas mudanças que sua força e seu poder político não mais podiam ser recompostos. 
Ocorre que a economia ervateira entrara, nessa década, em profunda crise. Primeiro, são os efeitos da crise mundial que se iniciara em 1929 e que reduz a demanda dos países compradores. A isso soma-se a entrada em produção dos ervais cultivados na Argentina, que reduzem significativamente a importação de erva cancheada pelo maior mercado do mate brasileiro. Ainda que o beneficiamento do mate seja menos atingido, o comércio exportador o é fortemente. E o que é mais importante, acirram-se os conflitos entre industriais de um lado e produtores e cancheadores do outro, organizando-se estes em cooperativas destinadas à defesa dos preços da matéria-prima, o que inaugura um conflito que, com as consequências políticas decorrentes, marcará a economia ervateira pelas décadas seguintes.

Isso leva a uma constatação importante: com sua fração de classe antes hegemônica não só afastada do poder, mas enfraquecida em sua base econômica, e com a fração que a substitui na cena política - porque as interventorias necessitavam de algum apoio para governar - não só desprovida de peso econômico significativo, mas com interesses e objetivos nem sempre coincidentes ou compatíveis com os que foram caracterizando o que poderíamos chamar de "projeto nacional" do novo bloco, o Paraná passa a viver uma situação nova. Ao longo das décadas seguintes os agentes principais de sua evolução serão mais vinculados aos interesses e objetivos do bloco no poder nacional, ou por eles influenciados, do que aos das frações locais. Isto, que é em parte decorrente da centralização de poder no Estado nacional, principalmente durante o Estado Novo e, como tal, fenômeno presente em todo o país, foi muito menos significativo ali onde classes ou frações de classes fortes participavam do poder nacional ou, mesmo dele excluídas, tinham de ser levadas em conta por indispensáveis para o sucesso de políticas e projetos de âmbito nacional.

Sobre essas mudanças logo se sobrepõe outra, de consequências muito mais marcantes: a expansão da cafeicultura. Ocupando e ampliando o espaço geográfico aberto por um grande projeto de ocupação de território e de colonização concebido e iniciado ainda nos anos vinte, essa expansão mudará radicalmente a fisionomia do Paraná, sua base econômica e sua sociedade, e a correlação de forças na política estadual. Lento no início, acelerando-se depois que os efeitos da Segunda Guerra Mundial voltam a estimular a produção de café, já no entorno de 1950 esse processo havia conseguido criar no norte do estado um outro Paraná, igual em tamanho e população, porém mais rico que o original, e o que é mais importante, socialmente diferente.

Fenômeno semelhante, ainda que com características econômicas e sociais muito diferentes, começa a ocorrer simultaneamente nas regiões Oeste e Sudoeste do Estado, que entre 1943 e 1946 lhe haviam sido subtraídas para a formação do Território do Iguaçu. Trata-se de 
contínua e crescente migração provinda das regiões coloniais do Rio Grande do Sul, formada principalmente por agricultores à procura de terras onde reproduzir seu sistema produtivo. De início, voltam-se majoritariamente para lavouras e criação de subsistência, gerando uma crescente oferta de madeira decorrente da derrubada necessária para a limpeza das terras a cultivar. Em muitos casos, simplesmente ocupam terras públicas ou de proprietários ausentes; em outros, compram lotes de companhias de colonização que se estabelecem na região. A questionabilidade e imprecisão de praticamente todos os títulos de propriedade existentes e negociados nessa parte do território estadual vai levar a uma sequência de graves conflitos rurais, que marcarão a década de 1950, mas o processo continuará a intensificar-se, criando o que já foi chamado de um terceiro Paraná.

O resultado de todas essas mudanças ocorridas a partir de 1930 é a multiplicação de novos agentes sociais, enquanto os já existentes passam por mudanças em suas formas de inserção na cena política estadual. Isso é tanto diretamente provocado pelas mudanças na base econômica ocorridas em nível local - como o fortalecimento das cooperativas dos produtores de mate, já referido, ou o crescimento e diversificação das classes médias urbanas - quanto reflexo de diversas políticas adotadas nacionalmente - como as políticas trabalhista e sindical do governo Vargas, por exemplo. Somem-se a essas causas as medidas de intervenção sobre as organizações surgidas entre as comunidades de imigrantes, decorrentes da política de afirmação nacional e reforçadas durante o período de guerra, e que atingiram mais diretamente as alemãs e italianas, justamente as mais fortes e organizadas.

Com isso, a partir do momento em que se inicia e consolida o processo de redemocratização, a sociedade paranaense já mostra um amplo leque de agentes sociais que passam a interferir de várias formas e em diferentes momentos no espaço político estadual. Esse novo quadro, que sofrerá poucas modificações até o início da década de 1960, como que lança as bases do Paraná atual, pois é nesse período que alguns dos principais agentes sociais hoje presentes começam a manifestar-se. Por essa razão é que, para os objetivos deste trabalho, merecem ser estudados de forma mais aprofundada.

Comecemos pelas classes sociais e suas frações, e pelos partidos políticos, sua forma mais própria e tradicional de organização. Ainda que seja extremamente difícil estabelecer com exatidão essas vinculações no caso brasileiro, algumas aproximações e generalizações são válidas, e já foram pesquisadas e comprovadas por diversos estudos realizados a esse respeito, apesar das inexatidões próprias às formas de articulação política predominantes no país.

Como em todos os estados, as facções políticas mais conservadoras que haviam apoiado o Estado Novo e participado dos governos dos interventores unem-se no Partido Social 
Democrático (PSD), que no Paraná representa grosso modo a fração burguesa cuja origem fora a propriedade da terra nos Campos Gerais - por imprecisa que essa definição seja - e que incorporara diversos segmentos da burguesia industrial beneficiados pelas políticas governamentais, principalmente no setor madeireiro.

Algumas facções da burguesia mais identificadas com as políticas de industrialização e por elas mais diretamente beneficiadas, assim como segmentos das classes médias, principalmente os diretamente ligados ao setor público e à política sindical de Vargas, bem como segmentos da pequena burguesia, juntam-se a amplos setores dos trabalhadores urbanos e aos componentes das estruturas sindicais organizadas a partir do Ministério do Trabalho, formando o Partido Trabalhista Brasileiro (PTB). No Paraná a força do PTB será maior nas cidades com razoável concentração de operários industriais, nos portos e nas cidades onde se localizam oficinas das estradas de ferro.

A burguesia comercial e financeira, bem como alguns segmentos da burguesia industrial, a maior parte da pequena burguesia e das classes médias tradicionais, além de facções dos grandes proprietários de terra que se haviam oposto a Vargas desde cedo, formam a União Democrática Nacional (UDN), que se coloca como o grande opositor ao regime getulista e à sua coalizão de apoio. Como grande defensora da reabertura democrática e da reinstauração do estado de direito liberal, a UDN inclui no começo forças de esquerda, lideranças populistas antigetulistas e núcleos dos velhos partidos anteriores a 1930, que após as eleições de 1945 seguem seus próprios caminhos. No Paraná, o núcleo original da UDN é a fração da burguesia industrial originária da erva-mate, que permanecia fora do poder desde 1930, e da qual parte logo se incorpora no recriado Partido Republicano. Ficam na UDN alguns segmentos dessa fração de classe e de partes significativas das burguesias comercial e financeira e das classes médias, bem como algumas facções dos proprietários de terra, principalmente na região cafeeira.

Por último, segmentos do operariado organizado, assim como da pequena burguesia e das classes médias, principalmente nos meios intelectuais, participam do recém-legalizado Partido Comunista (PCB), que permanece na legalidade por apenas pouco mais de dois anos. Sua presença no Paraná era restrita, com apoio limitado entre operários e componentes da pequena burguesia, principalmente em Curitiba, e alguma presença entre operários e trabalhadores rurais no norte do estado.

Além desses partidos, organizados nacionalmente, surgem outros, geralmente representando facções dissidentes ou lideranças políticas locais ou regionais. Dentre estes, terão presença significativa no Paraná o Partido de Representação Popular (PRP), com apoio nas camadas médias, o Partido Social Progressista (PSP), criado em torno de Adhemar de Barros em São Pau- 
lo e, consequentemente, ativo no norte do estado, mas também em Curitiba, e posteriormente o Partido Democrata Cristão (PDC).

Além dos partidos políticos, os principais agentes na defesa dos interesses de classe já eram as associações de classe e os sindicatos. No Paraná, desde o final do século XIX, a principal entidade representativa dos interesses da burguesia como um todo e de suas principais frações de classe era a Associação Comercial, onde, obviamente, o papel preponderante dos industriais e comerciantes de erva-mate fora-se erodindo, abrindo lugar para outras frações de classe agora mais dinâmicas. A ela somam-se, a partir da legislação sindical do Estado Novo, os sindicatos patronais e suas federações, no modelo corporativo até hoje vigente. Essas entidades, criadas em sua maior parte em função das exigências legais, e não a partir de suas próprias bases, permaneceram por muito tempo desempenhando papel secundário, sob a égide da Associação Comercial. Enquanto isso, com a expansão da economia cafeeira e o crescimento econômico do norte do Estado, a burguesia local se organiza em suas próprias associações comerciais e industriais municipais, enquanto a burguesia cafeeira, fração dominante na região, cria suas associações rurais, das quais a de Londrina será a mais importante. Esta, e a associação de classe dos cafeicultores, agindo sempre em conjunto, será seu principal instrumento de ação política, tanto na esfera estadual quanto na federal.

No que se refere às outras classes sociais, trabalhadores assalariados urbanos e rurais, colonos da cafeicultura, pequenos agricultores proprietários ou não, e as frações mais pobres da pequena burguesia, seu papel, como não podia deixar de ser, foi muito menos destacado em termos de ações reivindicatórias de qualquer tipo, ainda que o período seja marcado por alguns poucos momentos de acirramento de conflito entre as classes.

A fraqueza absoluta e relativa da classe operária, bem como o fato de os trabalhadores assalariados ainda representarem uma parcela minoritária do total da população economicamente ativa, já pode ser considerado um fator explicativo suficiente. Adicione-se a isso o fato de que os sindicatos operários das categorias mais fortes e melhor organizadas vinculavam-se politicamente ao PTB, o que significava que suas reivindicações tendiam a ser tratadas pelos canais internos do estado, principalmente pela via do Ministério do Trabalho. Os partidos e movimentos de esquerda, além de fracos e, no caso dos comunistas, ilegais, tinham pouca presença, e localizada principalmente entre intelectuais e pequenos burgueses.

É nesse quadro referencial que a política paranaense se desenvolve no período. A tentativa das frações industriais e comerciais da burguesia organizadas no PR e na UDN (e com apoio do PTB) de voltar ao poder local pela via eleitoral, em 1947, fracassa. Enfraquecidas pela longa hegemonia das frações rivais durante as interventorias, veem seu candidato - Bento Mu- 
nhoz da Rocha - derrotado por Moysés Lupion, do PSD, que obtém 59\% dos votos, contra apenas $29 \%$ do adversário.

Três anos depois o quadro se inverte, e, após duas décadas, essas frações voltam ao poder, ainda que não mais com a força hegemônica do passado, principalmente porque suas alianças na esfera nacional não têm a mesma permanência das que caracterizavam o período anterior a trinta. A vitória de Bento em 1950 (com 63\% dos votos) é em parte consequência de não ter hostilizado a candidatura Vargas, enquanto o PSD local apoia Cristiano Machado.

Cinco anos depois, quando as eleições ocorrem apenas um ano após o suicídio de Vargas, Lupion volta a eleger-se, principalmente em face da divisão entre os partidos que lhe opunham. Mas obtém apenas $41 \%$ dos votos, contra 29\% de Mario de Barros, do PTB, com o qual o PR se coligara, enquanto Othon Mader, da UDN, fica com 15\%. Essas eleições assinalam o final de uma era, a da longa disputa pela hegemonia no Estado entre as duas frações burguesas que se revezaram no poder desde a Emancipação. A base econômica do Paraná estava em rápida mudança; o mesmo ocorria com o Brasil, ainda que os dois processos não apontassem necessariamente na mesma direção, como veremos adiante.

Enquanto os principais agentes sociais agiam preferente e preponderantemente pela via partidária, e isso não significa somente os processos eleitorais, mas todas as redes de influência, pressão, clientela, negociações e compromissos, alguns segmentos que hoje chamaríamos de "excluídos" desse processo reuniam-se em movimentos sociais que, apesar de precariamente organizados e de curta permanência em cena, marcaram significativamente o período.

Como não podia deixar de ser, por tratar-se de camadas que, além de majoritárias, haviam permanecido efetivamente excluídas de qualquer tipo de participação ou beneficio na formulação e execução das políticas econômicas e sociais do bloco do poder formado no Brasil a partir de 1930, com pouco ou nenhum acesso aos canais partidários devido a seu limitado peso eleitoral, esses movimentos surgiram entre os trabalhadores e pequenos produtores rurais.

O primeiro desses movimentos surgiu com a resistência de pequenos produtores, que ocupavam e trabalhavam terras não tituladas nos limites ocidentais do chamado Norte Velho, à sua expulsão por grandes fazendeiros de café e cana-de-açúcar. Centrou-se em Porecatu e Arapoti, produzindo inclusive conflitos armados com a polícia estadual, entre o final da década de quarenta e o início da seguinte. Chegou a contar com apoio organizacional de membros do PCB, já na ilegalidade, mas, como seria de esperar, esgotou-se a partir das derrotas infligidas pelos jagunços e pela polícia. De uma certa forma sobreviveu em termos da experiência adquirida, que foi mais tarde utilizada na formação de sindicatos rurais em toda a região cafeeira.

Mais amplo, e com repercussões muito maiores, foi o movimento dos pequenos produtores do Sudoeste no final da década de cinquenta. Mais uma vez o problema principal era a questão da legitimação da posse da terra. Desde a extinção do Território do Iguaçu, e diante da crescente migração proveniente do Rio Grande do Sul, o governo estadual passara a agir diretamente no ordenamento da ocupação da área, por meio de seus aparelhos específicos, principalmente o Departamento do Oeste, depois Departamento de Fronteira. Como já vinha 
sendo feito há décadas, a política de colonização baseava-se na concessão de grandes extensões de terras públicas a empresas privadas, que as revendiam em lotes aos colonos, além de abrir picadas e organizar a fundação de cidades. Esta fora não só a maneira como se processara quase toda a colonização da região cafeeira, como também uma das formas preferidas de acumulação de capital por parte da burguesia local, associada ou não a grupos de outros estados. Aqui o mecanismo funcionou bem de início, mas logo defrontou-se com alguns problemas específicos: a intensidade do fluxo migratório, o interesse das empresas na exploração da madeira existente na enorme floresta que recobria a quase totalidade da área, as irregularidades na cessão e demarcação das terras públicas, e a superposição de títulos de propriedade.

Nesse emaranhado de pleitos conflitantes, alguns grupos e empresas utilizavam-se de grileiros e jagunços para garantir as terras, pressionar e expulsar posseiros, muitas vezes compradores legítimos de lotes. Por outro lado, a maior parte dos produtores provinha de uma classe de pequenos e médios proprietários já consolidada há gerações, e portanto muito mais politizada e consciente de seus direitos. São esses pequenos produtores que se organizam e se armam para resistir aos jagunços e, quando a polícia estadual intervém, reagem e, com o apoio da pequena burguesia e das classes médias das pequenas cidades da região, como Francisco Beltrão e Pato Branco, parte da qual migrara no mesmo processo, invadem e ocupam esses centros e desafiam o governo estadual.

Ainda que tenha surgido como movimento social espontâneo, logo se dá sua articulação com os partidos de oposição ao governo de Lupion, principalmente o PTB e a UDN. O resultado é a presença federal que, por meio do Exército, desarma o movimento, mas também aos jagunços, coíbe a ação das companhias de terra e depois inicia, em conjunto com o governo estadual, um longo processo de revisão, anulação e revalidação dos títulos de propriedade. No longo prazo, além de consolidar e ampliar a politização das classes envolvidas, o movimento servirá de exemplo para futuras mobilizações, como as dos sem-terra, décadas depois.

Antes de encerrar a análise desse período, vale lembrar outro tipo de movimento social, só que das classes dominantes: a "Marcha do Café". Sua origem localiza-se no que então era chamado de "confisco cambial", mecanismo pelo qual, por meio das políticas cambial, de comércio exterior e de fixação dos preços de aquisição do café aos produtores, parte da renda gerada pelo setor cafeeiro era apropriada pelo governo federal, formando um fundo de defesa do produto. Decorrente da necessidade de dispor de recursos para a aquisição de estoques reguladores e de restringir a oferta de café, em face das condições em que então se encontrava o mercado mundial desse produto, esse fundo significava também uma crescente massa de recursos financeiros à disposição do Tesouro, o que reforçava a capacidade de realizar investimentos públicos e de financiar a expansão industrial, duas das principais linhas de ação da política de desenvolvimento seguida pelo governo Kubitschek. 
Ora, se em nível do Estado brasileiro a mera possibilidade de executar uma política desse tipo traduzia simplesmente a perda relativa de poder das frações burguesas agroexportadoras no bloco no poder, em favor do capital industrial e financeiro, junto aos produtores seus resultados eram vistos como uma violência do governo. A princípio os cafeicultores, em todos os estados produtores, canalizaram suas reclamações e reivindicações pela via dos partidos, mas à medida que esse caminho, pelo seu próprio enfraquecimento como fração de classe, foi-se mostrando insuficiente, o segmento maior, mais importante e de expansão mais rápida e recente - os produtores do Paraná - resolveram, com algum apoio do governo estadual, organizar uma marcha com milhares de participantes para pressionar diretamente o governo no Rio de Janeiro. Fracassadas as tentativas de conciliação, a marcha iniciou-se, com grande publicidade e ampla mobilização. A presença de tropas do Exército, deslocadas para a fronteira entre o Paraná e São Paulo, esvaziou o movimento, que se dissolveu em seguida.

Ao iniciar-se a década de 60 as transformações da base econômica, tanto no Brasil quanto no Paraná, faziam prever mudanças e reacomodações na esfera política e mesmo no bloco no poder que, com sucessivos ajustes, vinha mantendo sua hegemonia no estado brasileiro desde 1930. Em termos estaduais, essas mudanças pareciam ainda mais prováveis, devido ao fato de que não só a composição de classes da sociedade havia mudado, como a fração no poder estava cada vez mais visivelmente enfraquecida em termos políticos.

As políticas governamentais seguidas pelo segundo governo Lupion, bem como as posições assumidas pelo PSD paranaense em relação às questões nacionais, pareciam como que atrasadas uma década em relação ao que ocorria no Brasil: a ideologia desenvolvimentista, que começara a ganhar forma no segundo governo Vargas, e se consolidara como hegemônica com Kubitschek, mal aparecia nas ações ou nas falas dos que detinham o poder no Estado.

O que vinha acontecendo no país pode ser sintetizado em poucas linhas: com o crescimento industrial, as frações industrial e financeira da burguesia, bem como os segmentos da burguesia rural voltados para o mercado interno, haviam se fortalecido; em contrapartida, o mesmo ocorrera com o operariado industrial e com outros segmentos das classes trabalhadoras urbanas, que elevavam os níveis de suas reivindicações. Por outro lado, a burguesia agroexportadora não só se enfraquecera, como passara a enfrentar o despertar dos trabalhadores e pequenos produtores rurais que, pela primeira vez, organizavam-se para conseguir sua inclusão no processo político e entre os beneficiados com o desenvolvimento. Como componente novo incluía-se, pela primeira vez, a forte e crescente presença do capital estrangeiro na produção para o mercado interno, o que, em certos aspectos, mudava o caráter "nacional" da burguesia.

O que citamos anteriormente como uma defasagem em termos do Paraná pode ser 
em parte explicado pelo fato de que no estado a situação era diferente: a economia paranaense vinha se expandindo, e de forma notadamente acelerada, exatamente como uma economia primário-exportadora; os segmentos industrial e financeiro da burguesia local vinham, consequentemente, enfraquecendo. No entanto, convém não esquecer que parte do fortalecimento da economia primário-exportadora do Norte devia-se a que ela também desempenhava cada vez mais o papel de exportadora interna de alimentos e matérias-primas de origem agrícola.

De qualquer modo, a aceleração do desenvolvimento econômico brasileiro e a crescente consciência de que a expansão econômica e demográfica por que passava o Paraná (com a rápida ocupação do território, o surgimento contínuo de novas cidades e a população dobrando a cada recenseamento) vinha multiplicando e agravando carências e deficiências, começa a mobilizar forças políticas e sociais para a necessidade de mudanças na forma de condução do estado.

As bases sociais dessa consciência e das propostas que dela surgiram eram exatamente as frações industriais, financeiras e comercial da burguesia, voltadas para o mercado nacional, e que viam o Paraná como que perdendo a oportunidade de aproveitar-se da prosperidade cafeeira para, como São Paulo o fizera, iniciar um processo de industrialização. Só que esse conjunto estava politicamente dividido: na região do café congregava-se principalmente em torno do PTB, fortalecido pelo controle que detinha dos aparelhos de estado federais mais importantes para a economia regional, ainda que alguns segmentos, como em Londrina, mantivessem-se ligados à UDN; no sul do estado era representado pela UDN e pelo PDC, este ainda pequeno, mas fortalecido pela liderança de Ney Braga, que de 1954 a 1958, como prefeito eleito de Curitiba, fizera uma administração eficiente.

Essa divisão leva ao surgimento das duas candidaturas de oposição às eleições de 1960: Maculan (que substitui Souza Naves, falecido) pelo PTB e Ney Braga pelo PDC. Em torno de ambas mobilizam-se diversos segmentos da sociedade, como intelectuais, técnicos dos aparelhos de estado, profissionais liberais e suas associações de classe, bem como participantes dos movimentos estudantis, apresentando estudos e propostas sobre o desenvolvimento do Paraná e a reorganização de seu setor público.

A vitória de Ney Braga é apertada (35\% dos votos, contra 31\% de Maculan e 27\% de Plínio Costa), mas traduz um sentimento majoritário pela mudança do papel do estado com vistas ao desenvolvimento, sentimento que é reforçado - ainda que com componentes diferentes - pela vitória de Jânio Quadros nas eleições presidenciais simultâneas.

O primeiro governo Ney Braga pode ser caracterizado como o momento em que o estado ganha, no Paraná, a configuração que mantém basicamente até hoje, não apenas pelo 
leque de aparelhos e instrumentos criados para fomentar o desenvolvimento econômico a atender às demandas sociais, como também pelos padrões de eficiência da ação de muitos desses aparelhos. Isso é importante sob dois aspectos: primeiro, e com efeitos de curto prazo, porque a ineficiência e precariedade dos aparelhos de estado, principalmente nas regiões de colonização recente (Norte, Oeste e Sudoeste), somadas ao seu isolamento em termos de transportes e comunicações, vinha sendo, no Norte, a causa básica do surgimento de um movimento de cunho separatista, visando à criação do Estado do Paranapanema, e que logo se esvazia; segundo, e muito mais importante, porque o conjunto de mecanismos de fomento e investimentos públicos implantados e realizados nesse período traduzem-se em forte apoio à acumulação de capital na economia paranaense, o que não apenas permitiu a manutenção de seu crescimento ao longo da fase de estagnação da economia brasileira na metade dos anos sessenta, como também permitiu a posterior superação da perda do dinamismo da economia cafeeira e a rápida expansão dos anos setenta.

A crise brasileira que se inicia na primeira metade da década de sessenta decorre do esgotamento do processo de industrialização por substituição de importações e da sua decorrente repercussão política, levando ao rompimento do bloco no poder, que só será recomposto após o golpe militar de 1964. O novo bloco terá seu eixo central na aliança entre o grande capital nacional e o capital monopolista mundial, principalmente o financeiro, com o enfraquecimento das frações médias e pequenas do capital nacional, preponderantemente o industrial, das frações burguesas agroexportadoras e dos grandes proprietários rurais. A classe trabalhadora como um todo, bem como a pequena burguesia e as classes médias, são parcial ou totalmente excluídas das áreas de poder que vinham ocupando, e os trabalhadores e pequenos produtores rurais veem frustradas suas esperanças de sair de sua tradicional exclusão.

No Paraná o resultado das eleições de 1960 rearticula o "bloco no poder" local a partir das frações industrial e financeira da burguesia, então já muito mais diversificadas, e associadas em maior ou menor grau ao grande capital nacional e estrangeiro. Esta é a força hegemônica que empalma e conduz o que alguns autores chamarão de "projeto" ou "modelo" paranaense de desenvolvimento, e que ganha apoio não só de quase todas as outras frações burguesas, principalmente nos segmentos mais dinâmicos da agricultura e da pecuária, como também de grande parte da pequena burguesia e das classes médias. A ideologia desenvolvimentista mostra-se forte o suficiente para levar a uma aliança entre os partidos de apoio ao governo (PDC, UDN e PL) e o PTB, que vence as eleições legislativas de 1962, depois de ter assegurada a aprovação do empréstimo compulsório que permitiu a criação do Fundo de Desenvolvimento Econômico e da CODEPAR, principal instrumento de ação econômica do Estado.

É em plena fase de demarragem dessas e outras ações desenvolvimentistas que se acir- 
ram os conflitos políticos e ideológicos que levam à deposição de Goulart. A postura majoritariamente conservadora da sociedade paranaense - decorrente da base econômica já referida - e a popularidade do governo estadual, que não apenas apoia mas é também politicamente ligado à corrente principal do movimento militar, explicam o apoio ou aceitação do golpe pela quase totalidade das classes dominantes e pela maioria da população. Somente os trabalhadores mais politizados, parte das camadas intelectuais e alguns dos segmentos efetivamente ligados ao PTB assumem posição contrária.

Há aqui um contraste com a reação à tentativa anterior dos então ministros militares de impedirem a posse de Goulart, quando da renúncia de Jânio Quadros. Em grande parte estimulado pela resistência pregada por Brizola em Porto Alegre, e ajudado pela prefeitura de Curitiba, então controlada pelo PTB, surge um movimento popular de apoio à posse de Goulart, que se mobiliza inclusive para arrecadar donativos em produtos para os soldados do Terceiro Exército que se deslocavam para a fronteira do Paraná com São Paulo. Esse contraste é em parte explicado pela grande mobilização promovida em todo o país pelas forças políticas que se opunham ao governo Goulart, principalmente as grandes marchas por Deus e a Família, conduzidas por segmentos da Igreja Católica, realizadas também no Paraná, bem como pelo crescimento do movimento conhecido como Sindicalismo Democrático, respaldado pela AFLCIO norte-americana que, presente em todo o Brasil, era particularmente forte no estado.

De qualquer maneira, o apoio majoritário ao governo estadual, quer por seu apoio ao golpe e ao governo dele resultante, que apesar disso, fica comprovado nas eleições de 1965, em que Pimentel é eleito com 51\% dos votos, contra 45\% de Bento Munhoz da Rocha, que representa uma coligação dos que eram oposição ao governo Castello Branco, principalmente o PTB, e as facções que, mesmo apoiando-o, eram contrárias a Ney Braga. Note-se que o Paraná foi o único dos grandes estados, com eleições nesse ano, onde venceu o candidato apoiado por um governo estadual que se havia colocado abertamente a favor da deposição de Goulart e do governo que o sucedeu.

Estamos já, então, no período autoritário. Do ângulo do estudo dos agentes sociais, isso vai significar que se iniciam mudanças significativas tanto nas relações de poder quanto nas relações com o poder e entre as esferas de poder. Qualquer análise do período 1964-1985 permite perceber que foi uma época de constantes conflitos políticos, tanto das forças sociais opostas ao autoritarismo contra este e suas diversas manifestações, como entre as forças que o apoiavam, inclusive dentro do próprio bloco no poder; conflitos esses que em muitos momentos se confundem, com contínuos remanejamentos de forças, até que as primeiras conseguem finalmente impor-se às últimas. É dentro desse quadro que se pode compreender o papel dos 
agentes sociais, seu desenvolvimento e sua multiplicação, tanto no Brasil como um todo quanto no Paraná.

Três fenômenos formam o pano de fundo principal para essa evolução: primeiro, a forte tendência para a centralização ampla e crescente de poder no seu núcleo central, o que no campo institucional significa o executivo federal, que representa o bloco no poder em termos políticos e o "sistema" em termos militares; segundo, a valorização crescente de critérios "técnicos" nos processos de formulação e execução de políticas públicas, deslegitimizando o campo da política, ainda que nas práticas governamentais as decisões continuassem sendo políticas, só que mascaradas pela opacidade do regime; e terceiro, e talvez o mais importante em termos do que viria a ser o Brasil após 1985, o esvaziamento e deslegitimação dos partidos como agentes sociais privilegiados, e o consequente fechamento ou abandono dos canais partidários como vias de reivindicação e ação para e pelos múltiplos grupos sociais.

Vamos analisar cada um desses fenômenos e suas repercussões no Paraná.

A centralização de poder no governo federal, principalmente no seu braço executivo, correspondia ao objetivo maior tanto do bloco no poder quanto do projeto nacional formulado a partir das doutrinas da Escola Superior de Guerra, qual seja, a criação de um Brasil capitalista moderno e forte, associado ao bloco capitalista mundial liderado pelos Estados Unidos. O que já foi chamado de modernização conservadora. Para a consecução desse objetivo, era fundamental não só superar a situação de crise que o país vivia em meados dos anos sessenta, como também mobilizar aceleradamente os meios disponíveis para a retomada da acumulação de capital necessária ao crescimento da capacidade produtiva.

Ora, no federalismo brasileiro, parte desses recursos era direta ou indiretamente controlada pelos governos estaduais, isto é, pelas frações de classe que detinham o poder nessa esfera. Como nem sempre os interesses e objetivos dessas forças coincidiam, ou coincidiriam no futuro com os do bloco no poder, mesmo aquelas que apoiavam politicamente o governo precisavam, nessa ótica, ter sua capacidade de ação limitada, ou poderiam vir a retardar o desenrolar do processo, podendo até mesmo detê-lo ou invertê-lo.

No plano político isso traduziu-se, após as eleições de 1965, na escolha indireta dos governadores, depois ampliada para as prefeituras das capitais e de algumas cidades importantes ou estratégicas. No Paraná, isso significou o enfraquecimento das facções políticas em que se dividiam as frações de classe no poder local, com a marginalização das lideranças de Ney Braga e Pimentel. Já em 1970 a escolha é feita com a clara intenção de completar o esvaziamento do poder local. Só a partir de 1974 é que, iniciado o processo de "distensão" com o governo Geisel, as forças políticas locais voltam a ser levadas em conta. 
No plano econômico, a centralização se manifesta em múltiplas formas. O Paraná escapou de golpes diretos drásticos, como a cassação do governador de São Paulo, Adhemar de Barros, que parece ter sido causada principalmente por sua utilização de seu banco estadual para contrarrestar a política recessiva adotada para derrubar a inflação. Mas sucessivas medidas do governo federal afetam diretamente os interesses das frações da burguesia local que o apoiavam, enfraquecendo-as, como a drástica redução dos preços de aquisição do café pelo IBC em 1966, ou o dispositivo, incluído na Constituição de 1967, que vedou aos estados o lançamento de empréstimos compulsórios. Essa medida praticamente liquidou o principal instrumento de execução da política de desenvolvimento do estado, o FDE, com cujos recursos financiava-se a acumulação da burguesia industrial local, e seguiu-se a uma decisão local, mas decorrente da crescente hegemonia ideológica do bloco no poder nacional, a de revogar o dispositivo que vedava a concessão de financiamentos a empresas estrangeiras. Com essas medidas, a burguesia industrial local se enfraqueceu, e não apenas pela redução de seu ritmo de expansão, mas, também, por ter de ceder espaços ao grande capital, tanto nacional quanto estrangeiro, à medida que, com a redução dos recursos do FDE, a CODEPAR cada vez mais passou a depender da captação, via avais, de recursos externos.

Outro aspecto da centralização foi a criação de organizações sistêmicas dos aparelhos de estado federais e estaduais em grande parte das áreas dependentes de políticas públicas, sob o comando centralizado dos primeiros, que detinham a maior parte dos recursos financeiros e do poder normativo. Apenas como exemplo, isso ocorreu no caso do saneamento urbano, das telecomunicações, do sistema elétrico, dos portos, dos aparelhos de segurança e até no modelo organizacional das burocracias estaduais. A forma como essa centralização funcionou significou, entre outras consequências, a perda de espaços políticos para muitas das frações de classe locais e as facções políticas que as representavam.

Esse aspecto do primeiro fenômeno referido sobrepõe-se ao segundo, isto é, a valorização dos critérios técnicos, pois foi em nome da "eficiência" que as estruturas sistêmicas foram montadas. A falsa aporia entre a racionalidade das decisões técnicas e o imediatismo interesseiro das decisões políticas foi aqui claramente utilizada para deslegitimar os reclamos e reivindicações dos agentes sociais afetados ou prejudicados por decisões e políticas que beneficiavam outros agentes. Dois casos marcantes desse fenômeno mereceriam maiores estudos: a adoção do projeto de Itaipu para o aproveitamento hidroelétrico do desnível do Paraná abaixo de Guaíra e a escolha do Rio Grande do Sul para a implantação do terceiro pólo petroquímico. Ambas as decisões foram tomadas sem o debate aberto entre os interessados, justificadas tecnicamente, e fortemente influenciadas por considerações políticas que sequer foram publicizadas. 
Ainda que muitas outras decisões, tanto do governo federal quanto do estadual, que a partir de 1970 assume o discurso da superioridade do técnico sobre o político (que transparece também, com toda a clareza, no discurso e nas ações de Jaime Lerner quando de sua primeira gestão como prefeito de Curitiba, por exemplo), também tenham sido assim justificadas, a consequência mais importante para os objetivos deste estudo foi a incorporação e valorização pelos aparelhos de estado de quadros de técnicos e de especialistas de formação universitária em nível jamais antes alcançado no Brasil ou no Paraná, o que, por sua vez, trouxe seus órgãos e associações de classe ao primeiro plano como agentes sociais.

Quanto ao terceiro fenômeno, o esvaziamento e deslegitimação dos partidos e dos canais partidários, merece uma análise mais aprofundada, principalmente pelas consequências de médio e longo prazos que disso adviriam. Antes, porém, é necessário fazer algumas reflexões sobre dois pontos importantes relativos às características dos partidos brasileiros e ao papel dos partidos na atual fase de evolução social e política do mundo.

Ainda é frequente encontrar referências e opiniões relativas aos partidos brasileiros do passado, como sempre tendo sido meras legendas acomodatícias de interesses de pessoas ou grupos que pouco teriam em comum além de objetivos imediatos no jogo do poder político. Ainda que opiniões desse tipo sempre fossem predominantes em cada época, e que a legislação eleitoral sempre permitisse partidos que em determinados momentos ou regiões desempenhassem esse papel, alguns dos estudos e pesquisas mais completos e aprofundados que vêm sendo produzidos e publicados permitem questionar essa visão. O que transparece dessas análises é que, principalmente no período de generalização de práticas democráticas, entre 1945 e 1965, os grandes partidos de âmbito nacional, como PSD, UDN e PTB, os que cresceram a partir de bases regionais, ou a elas ficaram limitados, como PSP, o PDC e o PR, e mesmo alguns que se restringiram inicialmente a bases regionais limitadas, como o PL, foram realmente partidos no sentido atribuído ao termo nas ciências sociais, ou seja, representantes e porta-vozes dos interesses concretos de classes, frações de classe ou camadas da população, defendendo e vocalizando suas reivindicações na cena política, não muito diferentes de seus congêneres europeus e, principalmente, norte-americanos. E isso sem falar nos partidos de cunho nitidamente ideológico, como o PCB, o PRP e o PSB.

Por outro lado, a literatura mais recente vem de há algum tempo frisando a diminuição do papel dos partidos nas sociedades democráticas desenvolvidas, partindo de análises que se centram na perda relativa de relevância do conceito de classe nas lutas políticas, ou da constatação da crescente presença de movimentos sociais poli ou transclassistas que, mesmo quando se organizam em partidos, agem para além dos limites partidários ou inteiramente fora deles. 
Essas considerações são importantes para entender o que acontece no Brasil a partir de 1965 quando, preocupado com as vitórias oposicionistas em Minas Gerais e na Guanabara, o governo autoritário entra em crise, e a resolve pela dissolução dos partidos existentes e a imposição de um sistema bipartidário artificial.

A montagem de dois únicos partidos por imposição de um regime autoritário, definindo-se de início um como sendo favorável e o outro contrário, torna difícil a própria constituição do segundo. No Paraná, com exceção dos políticos ligados ao PTB, a maioria dos pertencentes aos outros partidos filia-se à ARENA, que se torna majoritária no Estado, vencendo as eleições parlamentares de 1966 e 1970. Ainda que seus candidatos ao Senado sejam derrotados em 1974 e 1978, a legenda permanece majoritária nas eleições para a Câmara dos Deputados e para a Assembléia Legislativa nesses dois pleitos.

Tanto ARENA como MDB, apesar de atenderem aos aspectos formais da legislação partidária, não desempenham o papel efetivo de partidos. O primeiro porque, pelo menos até iniciar-se o processo de distensão política, no governo Geisel, não é o canal privilegiado das classes dominantes, menos ainda das que compõem o bloco no poder. As rivalidades internas entre as facções que dele fazem parte são amortecidas e, quando necessário, arbitradas pelo poder central. Seu papel principal é garantir ao Executivo maioria no Congresso, o que, com notáveis exceções, é sempre aceito por seus representantes. Já o MDB, cuja estruturação se dá com dificuldades, e que só com as eleições de 1974 passa a ter um desempenho eleitoral significativo, desde cedo se caracteriza como "frente" mais do que como partido, à medida que os grupos e facções que o compõem tendem a agir de acordo com seus próprios interesses, unindo-se somente quando se trata de marcar posição enfrentando o governo. Além do que, pelo menos até 1982, vive a situação paradoxal de um partido que não pode acessar ou ascender ao poder, o que, de plano, neutraliza seu papel de partido.

É em decorrência desse quadro que os agentes sociais começam a procurar ou a criar outros canais com o poder e outras formas de apresentar suas reivindicações, defender seus interesses e apresentar suas propostas. Após um período de retração da sociedade civil diante do poder do regime autoritário e de percepção da mudança das regras decorrente do esvaziamento partidário (que se traduz pelo grande contingente de votos brancos e nulos em todas as eleições, chegando, no Paraná, a cerca de 30\% em 1970), os diversos agentes começam a organizar-se em movimentos sociais, compostos por pessoas que se aliam em função de objetivos definidos e limitados, num corte vertical que muitas vezes une participantes de classes, posições políticas e filiações partidárias bem diferenciadas.

Um dos caminhos iniciais seguidos pelos segmentos sociais que se sentem excluídos 
ao verem bloqueados seus acessos à ação política é a organização de grupos ou movimentos clandestinos, muitos dos quais se transformam em pequenos partidos revolucionários de inspiração marxista. No Paraná, dadas as características já mencionadas de sua sociedade, sua presença é pequena, e geralmente surge em função de contatos com os grupos e movimentos de outros estados. Alguns se dedicam a analisar a situação nacional e a divulgar em meios restritos suas ideias e interpretações. Outros participam da luta política do movimento estudantil, conseguindo forte presença em alguns de seus segmentos, principalmente nas universidades. Outros ainda pregam a reação armada ao regime autoritário, mobilizam e recrutam quadros para ações em outras regiões do país. É preciso lembrar que tudo isso era feito sob a ameaça concreta dos aparelhos repressivos do Estado, sempre ameaçadoramente presentes e atuantes. Seus quadros vinham principalmente da pequena burguesia e das classes médias, inclusive de entre os técnicos que em número cada vez maior trabalhavam no próprio estado e entre intelectuais em geral, sendo sua ação maior entre os estudantes. Apesar dos esforços de muitas dessas organizações, sua penetração na classe trabalhadora, quer na cidade, quer no campo, foi sempre muito limitada, e quando ocorria, jamais divulgada.

Com a retomada do crescimento econômico de forma acelerada após 1967, quando se inicia o chamado "milagre" e o "bloco no poder" alcança por algum tempo a possibilidade de impor sua hegemonia ideológica à sociedade, e a repressão recrudesce após o AI-5, no final de 1968, essa combinação de fatores enfraquece e leva à extinção a maior parte desses grupos e movimentos.

Concomitantemente a esses movimentos começava a surgir todo um leque de agentes sociais que tinham em comum a inspiração e, em muitos casos, o apoio ou mesmo a participação direta de setores cada vez mais presentes e atuantes da Igreja Católica. De certa forma a ala chamada de "progressista" do clero, inspirada no que vinha ganhando forma como teologia da libertação, ou seja, uma reafirmação dos compromissos sociais da Igreja, passara a ocupar muitos dos espaços de defesa dos interesses e aspirações das camadas pobres da sociedade que os partidos haviam abandonado.

O leque desses movimentos foi, e ainda é, muito grande. Inclui as ações da Pastoral da Terra, que será um dos elementos básicos para a organização inicial dos movimentos dos sem-terra, na medida em que a expansão da soja e do trigo gera a concentração da propriedade fundiária na maioria das regiões agrícolas do Paraná ao longo da década de setenta. Inclui também as comunidades eclesiais de base, que congregarão principalmente os moradores das crescentes periferias urbanas, como na Região Metropolitana de Curitiba, assim como movimentos em defesa dos presos políticos e de denúncia de torturas e desaparecimentos, que se 
tornarão, com a abertura política, movimentos em defesa das condições de vida e dos direitos dos presos comuns.

Outro movimento social significativo que começou a surgir e veio a consolidar-se nessa época, com a criação da ADEA no início dos anos setenta, foi o dos defensores do meio ambiente ou ambientalistas, depois conhecidos como ecologistas ou "verdes". Nesse caso a postura não era de oposição política ao governo, mas de críticas centradas principalmente nas repercussões ambientais das grandes obras públicas e na inoperância das autoridades responsáveis pela conservação das florestas e pela qualidade das águas. O movimento se inicia entre técnicos dos órgãos estaduais de florestas e de recursos hídricos e pesquisadores acadêmicos, mas logo ganha crescente apoio em diversas camadas sociais. Seu papel mais importante foi a participação, junto com diversos outros agentes sociais, nas lutas para minorar os efeitos da construção de Itaipu sobre o meio ambiente e a população da região atingida, estendendo-se depois, com sucesso, à defesa da Serra do Mar e à exigência prévia de relatórios de impacto ambiental antes de construção de grandes obras.

Igualmente importante é o movimento dos sem-terra, que surge em meados da década de 1970. Sua formação incorpora a experiência das lutas dos anos cinquenta no Sudoeste e o apoio e inspiração da Igreja. Ainda no período autoritário legitimava-se no plano do discurso por defender a aplicação da legislação vigente referente à reforma agrária, o Estatuto da Terra, do governo Castello Branco, estratégia que continuou a seguir nos governos posteriores, principalmente no período Sarney. Extremamente militante, suas táticas de luta incluíam, depois da abertura política, marchas, invasão e ocupação de terras, acampamentos ostensivos em Curitiba ou à margem das principais estradas. Seu principal papel foi manter a mobilização dos trabalhadores e pequenos produtores, forçando por meio da pressão social medidas governamentais, tanto federais quanto estaduais, que dificilmente teriam sido tomadas sem sua luta.

A esses movimentos vieram somar-se, durante o período de abertura política dos governos Geisel e Figueiredo, diversos outros movimentos sociais que desempenharam, e ainda desempenham, papel importante no atendimento de reivindicações específicas dos grupos e camadas sociais que representam. Entre tantos cabe apenas, nos limites deste trabalho, mencionar os que tiveram atuação mais marcante em termos de resultados e de repercussão na sociedade: as associações de bairro, de diversos tipos e com reivindicações e formas de ação diferenciadas; as organizações dos mutuários do Sistema Federal de Habitação, em defesa de reajustes de prestações nos limites da capacidade de pagamento das famílias de rendas mais baixas e mais prejudicadas nos períodos de inflação alta, que seriam comuns a partir dos últimos anos da década de oitenta; os movimentos em defesa da cidadania, dos direitos do consumidor, dos direitos da 
criança e dos menores de rua e dos direitos da mulher.

Além dos movimentos sociais mencionados, o esvaziamento partidário abriu caminho para a ampliação da participação de outros agentes sociais, como as organizações profissionais e de classe. Em quase todas as lutas políticas contra o regime autoritário antes mencionadas, bem como nas de reivindicações pelo aprofundamento e aceleração da abertura política, como as campanhas pela anistia e pelas eleições diretas, agentes desse tipo estiveram presentes, assim como na apresentação, debate e encaminhamento de propostas para o futuro do Brasil e do Estado, além das lutas pelas reivindicações específicas de cada uma.

Entre esses agentes, cabe mencionar a $\mathrm{OAB}$, assim como os conselhos, ordens ou institutos de outras categorias profissionais, como arquitetos, agrônomos e economistas. O mesmo se deu com associações como a dos professores estaduais e dos professores das universidades, inclusive a Federal do Paraná, onde os docentes fazem a primeira greve de sua história. Além disso, associados ou membros de todas essas instituições participavam ativamente em um ou mais dos movimentos sociais antes mencionados.

Essa expansão e multiplicação de movimentos sociais de todo tipo, bem como a transformação de agentes sociais em personagens da cena política, é um fenômeno comum à maior parte dos países da América Latina entre as décadas de sessenta a oitenta, principalmente ali onde se instauraram ditaduras ou regimes aberta ou mascaradamente autoritários. Sua importância foi menor apenas onde os partidos políticos tinham longa tradição representativa e amplas bases de apoio. No Brasil, ao extinguir os partidos tradicionais, com o claro objetivo de aumentar o controle do bloco no poder sobre a vida política do país e enfraquecer o poder das frações de classe que, mesmo apoiando-o, poderiam opor-se a medidas que prejudicariam seus interesses, o regime acabou por criar, involuntariamente, condições para uma politização de amplas parcelas da população brasileira numa extensão nunca antes registrada. E mais, essa politização manifestou-se fora dos mecanismos decisórios e dos princípios de coesão que caracterizam a organização e funcionamento dos partidos, tornando-se com isso muito mais vocalizada e ativa.

A partir de 1982, por mais que ainda com restrições, a abertura política consolida-se com as vitórias eleitorais do MDB em alguns dos estados de maior peso econômico e político. $\mathrm{O}$ bloco no poder havia perdido parte de sua força hegemônica a partir da redução do crescimento econômico resultante da elevação dos preços do petróleo e das taxas de juros na economia capitalista mundial, que entrara no longo período de crise do qual ainda não saiu, e que no Brasil ganhava a feição de crise da dívida e de financiamento do setor público. Mas, reforçado pela incorporação da burguesia industrial e agroindustrial, principalmente de seus segmentos 
exportadores, e pelo ritmo de investimentos públicos que, mesmo reduzido, ainda se mantinha temerariamente elevado, o bloco no poder parecia ainda ter forças suficientes para manter-se coeso e hegemônico, mesmo com a vigência das regras democráticas.

O agravamento da crise econômica e suas repercussões dentro do bloco no poder, bem como o sucesso da intensa mobilização popular promovida pelos partidos oposicionistas para a campanha das Diretas Já, alteraram o quadro, resultando na vitória de Tancredo Neves e no governo Sarney. Completava-se a restauração democrática, cujo coroamento seria a Constituinte de 1986 e a Constituição de 1988. Esse o quadro referencial atual.

O bloco no poder não se rompe, tudo indica que apenas se amplia e muda a correlação de forças entre as classes e frações de classe que o compõem. Ainda há poucos estudos sobre este período, mas parece fora de dúvida que o grande capital, em suas frações industrial e financeira, continua o componente principal, ainda que perdendo espaço para outras frações da burguesia que se incorporaram ao bloco, e tenha tido sua liberdade de ação reduzida pelo retorno das práticas políticas democráticas, o mesmo podendo dizer-se das frações mais ligadas ao capital monopolista mundial, que já vinham perdendo a força que haviam tido logo após 1964. A relutância com que o Brasil vem aceitando a implantação do modelo neoliberal comprova esta análise sucinta.

No Paraná a análise desse período é ainda mais difícil. Mas pode-se afirmar que o bloco hegemônico, reconstruído em 1960 em torno da burguesia industrial e financeira local, rompe-se na medida em que os capitais médios locais sentem-se afetados pela penetração cada vez maior do grande capital na economia do estado, e a ela procuram resistir. Por outro lado, as frações ligadas à economia cafeeira veem seu poder significativamente reduzido pela perda da importância relativa de sua base, enquanto se fortalecem as frações associadas aos complexos agroindustriais, que têm nas cooperativas e em sua organização um dos mais importantes agentes sociais do estado.

Mas a mudança mais importante da restauração democrática é o retorno dos partidos políticos, com a consequente reconstituição dos canais partidários como vias de reivindicação e ação para os diferentes grupos e agentes sociais. Só que, após mais de três lustros de vida partidária, eles ainda não retomaram a posição privilegiada que detiveram até 1965.

Não cabe aqui aprofundar a discussão da pouca representatividade e da heterogeneidade e falta de coesão interna de grande parte dos partidos criados após 1979. Pode-se supor que isso é em parte consequência do fato de que os partidos que dominaram a vida política antes de 1965 não foram realmente extintos, ou obrigados a sobreviver clandestinamente, com seus quadros e lideranças banidos da participação na vida política; quadros e lideranças foram 
obrigados a reacomodar-se em duas legendas criadas artificialmente e, o que pode ser um fator explicativo de peso, onde, mesmo na ARENA, sua capacidade de interferir efetivamente na formulação, execução e crítica às políticas e ações governamentais era muito limitada, com o que se descolaram dos grupos e camadas que representavam, ganhando uma autonomia pessoal incompatível com a coesão partidária.

Além disso houve uma clara determinação do governo ao final do regime autoritário de impedir a reconstituição dos antigos partidos: até os dois partidos do bipartidarismo oficial tiveram de mudar de nome, e foi montada uma manobra jurídica para impedir que Brizola liderasse um PTB renascido. E mais, as facilidades posteriormente estabelecidas para a fundação de partidos levaram à proliferação de legendas sem representatividade, algumas das quais vieram a desempenhar o papel de legendas “de aluguel”, ou de venda de espaço na propaganda gratuita.

É interessante observar que ao romper-se o PDS, em face da disputa interna pela candidatura às eleições indiretas de 1985, o corte se deu aproximadamente entre o que haviam sido PSD e UDN. O primeiro já não tinha possibilidade de reconstituição real, em face das mudanças ocorridas em sua base social, o segundo praticamente renasce no PFL, incorporando lideranças sobreviventes de outros partidos pré-1965. Essa transposição quase completa faz com que o PFL venha sendo o mais coeso e homogêneo dos atuais partidos burgueses na esfera nacional, ainda que não no Paraná.

O PMDB foi gradativamente perdendo facções, primeiro como consequência natural de sua condição de "frente", depois por um processo de desintegração decorrente das lutas entre facções de caráter predominantemente local e personalista. Por outro lado, incorporou o PP, que ao ser fundado parecia destinado a tornar-se o partido nacional das frações burguesas opostas ao predomínio do grande capital, o que aconteceu no Paraná, onde incorporou a facção liderada por Jaime Canet, um pouco na linha do antigo PR, mas que desapareceu ao fundir-se ao PMDB como resposta à obrigatoriedade do voto vinculado nas eleições estaduais de 1982.

Após a eleição de Sarney, o PMDB, tanto no plano nacional quanto nos estados, sofreu o primeiro grande "inchaço" de adesões de políticos motivadas apenas pelo acesso direto às fontes do poder, fenômeno que se tornou comum a partir de 1985, atingindo depois o PRN de Collor e, agora, o PSDB de Cardoso. Esse comportamento, que enfraquece a coesão partidária, descaracteriza os partidos e debilita sua representatividade, ainda que não seja novo na política brasileira, jamais tinha alcançado a intensidade que vem apresentando agora.

A única exceção significativa a essa descaracterização dos partidos é o PT. Surgido da união do movimento sindical operário mais bem embasado socialmente no país com diversos 
dos fortes movimentos sociais dos anos setenta, e apesar de seus conflitos internos, é o único dos grandes partidos com fortes mecanismos de manutenção de sua coesão interna, efetivamente vinculado a linhas programáticas, e efetivamente preocupado em saber e publicizar a quem representa. No Paraná, dada a base social já tantas vezes referida, seu peso é limitado às áreas de atuação de alguns dos movimentos sociais que participaram em sua formação.

O outro partido nascido dos movimentos sociais, o dos ecologistas, ao contrário do ocorrido em alguns outros países, não conseguiu transferir para si o apoio da multiplicidade de grupos que defendem os mesmos objetivos.

No que se refere ao Paraná, a dificuldade de análise das vinculações de classes e frações de classe com partidos é ainda maior. Em parte, e esse é um tema ainda não estudado, talvez isso se deva à crescente integração de sua economia com as dos estados vizinhos, notadamente São Paulo, apagando as diferenças regionais entre as mesmas frações de classe. Não há dúvida de que a burguesia industrial e financeira, associada ou não ao grande capital nacional ou estrangeiro, aí incluídos grupos paranaenses que já ingressaram na esfera do grande capital, reforçada pela burguesia dos chamados complexos agroindustriais, que por sua vez interage com a burguesia rural, formam um tipo de "bloco no poder", ainda que tenha sido difícil identificar sua participação na cena política pela via partidária durante os três períodos sucessivos de governos do PMDB.

Esse partido manteve no Paraná as características de "frente", incluindo facções representativas do capital local, segmentos da pequena burguesia e das classes médias novas e tradicionais, bem como representantes de muitos dos movimentos sociais anteriormente analisados. Ao mesmo tempo abriu-se a representantes de muitas das frações de classe do "bloco no poder" referido, principalmente no que se refere à agroindústria e às cooperativas. Sucessivas defecções e cisões vêm alterando esse quadro e, ao enfraquecer o partido, abriram caminho para sua derrota em 1994.

Enquanto isso, é possível, grosso modo, encontrar facções políticas que representam os componentes do hipotético "bloco no poder" no Paraná, em partidos programaticamente tão díspares quanto PDT, PSDB, PTB e PFL.

Por outro lado, apesar do nítido crescimento das relações de trabalho capitalistas no campo, do aumento do número de trabalhadores na indústria no seu sentido amplo, da crescente urbanização, acompanhada da expansão da população marginalizada, os partidos que pretendem representar as classes trabalhadoras continuam eleitoralmente limitados. Mesmo o PT, que inclui uma base entre trabalhadores e pequenos produtores rurais, principalmente no Sudoeste, só recentemente apresentou crescimento significativo, principalmente com sua vitó- 
ria em Londrina.

Essa inconsistência partidária explica por que os movimentos sociais e as associações de classe de todo tipo, bem como as associações e sindicatos profissionais, ou seus representantes, filiam-se a partidos sem perder sua identidade e sem abrir mão de sua liberdade de ação. De certa forma, criou-se uma representatividade política truncada e instável e, por isso mesmo, pouco confiável, o que enfraquece ainda mais a própria representatividade de todos os envolvidos, cada vez mais vistos pela opinião pública, isto é, pelo eleitorado, como defensores de interesses pessoais e de grupos, o que alguns estudiosos já apontam como um risco à permanência dos aspectos formais da democracia. Bons exemplos dessa incapacidade de os partidos assumirem integralmente seu papel de principais agentes sociais, entre muitos outros, foram o movimento que ficou conhecido como dos "caras pintadas", pelo impeachment de Collor, em que só os partidos de esquerda participaram como tais, e a recente marcha dos ruralistas a Brasília, sem qualquer apoio (ou oposição) partidária.

\section{REFERÊNCIAS}

AUGUSTO, M. H. O. Intervencionismo estatal e ideologia desenvolvimentista. São Paulo: Símbolo, 1978.

CARNEIRO, D. Fasmas estruturais da economia do Paraná. Curitiba: Universidade do Paraná, 1962.

CARNOY, M. Estado e teoria política. Campinas: Papirus, 1990.

CASTAÑEDA, J. D. Utopia desarmada. São Paulo: Companhia das Letras, 1994.

COSTA, O. R. G. Ação empresarial do Barão do Serro Azul. Curitiba: Grafipar, 1981.

COSTA, S. G. A erva-mate. Curitiba: Scientia et Labor, 1989.

CRUZ, S. V.; MARTINS, C. E. De Castelo a Figueiredo: uma incursão na pré-história da "abertura”. In: SORJ, B.; ALMEIDA, M.H.T. Sociedade e política no Brasil pós-64. São Paulo: Brasiliense, 1983. p. 13-61.

DREIFUSS, R. A. 1964: a conquista do estado. Rio de Janeiro: Vozes, 1981.

EVERS, T. Sobre o comportamento das classes médias no Brasil. In: KRISCHKE, P. Brasil: do milagre à abertura. São Paulo: Cortez, 1982. p. 83-119.

IPARDES. Paraná: economia e sociedade. Curitiba, 1982.

IPARDES. O Paraná reinventado: política e governo. Convênio IPARDES, SEPL, FUEM. Curitiba, 1989.

LEÃO, I. Z. C. O Paraná nos anos setenta. Curitiba: IPARDES: CONCITEC, 1989.

LINHARES, T. História econômica do mate. Rio de Janeiro: J. Olympio, 1969. 
MAGALHÃES FILHO, F. de B. B. de. Evolução histórica da economia paranaense. Revista Paranaense de Desenvolvimento, Curitiba : BADEP, n.28, p.31-52, jan./ fev. 1972.

MAgALHÃES FILHO, F. de B. B. de. O Paraná em revista. Revista Paranaense de Desenvolvimento, Curitiba: IPARDES, n.82, p.5-16, maio/ago. 1994.

O’DONNELL, G. et al. O estado autoritário e movimentos populares. Rio de Janeiro: Paz e Terra, 1979.

O'DONNELL, G.; SCHMITTER, P. C. Transições do regime autoritário: primeiras conclusões. São Paulo: Vértice, 1988.

PADIS, P. C. Formação de uma economia periférica: o caso do Paraná. São Paulo: HUCITEC; Curitiba: SECE, 1981. 
